\title{
Improving the Economic Values of the Recycled Plastics Using Nanotechnology Associated Studies
}

\author{
W.S. Khan, R. Asmatulu*, S. Davuluri, V.K. Dandin
}

Department of Mechanical Engineering, Wichita State University, 1845 Fairmount, Wichita, KS 67260-0133, USA

[Manuscript received November 29, 2013, in revised form February 24, 2014]

*Corresponding author: Assoc. Prof., Ph.D.; Tel.: +1 316 9786368; E-mail address: ramazan.asmatulu@wichita.edu (R. Asmatulu).

Recycled polystyrene (PS) cups were chopped up and separately incorporated with multiwall carbon nanotubes (MWCNTs) and $\mathrm{NiZn}$ ferrite $\left(\mathrm{Ni}_{0.6} \mathrm{Zn}_{0.4} \mathrm{Fe}_{2} \mathrm{O}_{4}\right)$ nanoparticles prior to electrospinning under different conditions. These nanoscale inclusions were initially dispersed well in dimethylformamide (DMF), and then known amounts of the recycled PS pieces were added to the dispersions prior to $30 \mathrm{~min}$ of sonication followed by $4 \mathrm{~h}$ of high-speed agitation at $750 \mathrm{r} / \mathrm{min}$. The thermal, dielectric, surface hydrophobic, and magnetic properties of the resultant nanocomposite fibers were determined by thermal comparative, capacitance bridge, vibrating sample magnetometer (VSM), and goniometer techniques, respectively. Test results confirmed that the physical properties of recycled nanofibers were significantly increased as a function of the inclusion concentrations, which may be because of their excellent properties. The consumption of polymeric products as well as their waste materials has dramatically grown worldwide. Although plastic recycling, reprocessing, and reusing rates are growing, the physical properties and economic value of recycled plastics are significantly low. Consequently, this work provides a detailed explanation of how to improve recycled plastics, making them into highly valued new nanoproducts for various industrial applications, including filtration, textile, transportation, construction, and energy.

\section{KEY WORDS: Recycled polystyrene; NiZn ferrite; Multiwall carbon nanotubes (MWCNTs); Electrospinning; Nanocomposite fibers; Physical properties}

\section{Introduction}




\subsection{General background}

Recycling is an important activity involving the minimization of waste materials created by daily human activities ${ }^{[1]}$. Plastic recycling is the process of treating waste plastics to make new products with different properties compared to their virgin counterparts. The value of recycled plastics is generally low, limiting their reuse in the market ${ }^{[2]}$. In the U.S., nearly 75 billion pounds of plastic and plastic-related products are produced every year, and unfortunately a large percentage of this plastic ends up in large landfills. The U.S. recycles about $5 \%$ of its plastic products; however, 55\% of plastic products could be recycled if economically feasible methods were available to collect and reprocess the waste streams ${ }^{[1]}$.

Recycling and remanufacturing plastics have been major topics for many years because of the significant industrial importance. Without recycling and remanufacturing, many valuable resources will be either corroded or degraded, subsequently resulting in many environmental concerns $^{[2,3]}$. Plastic recycling saves the environment by reducing greenhouse gases, water and air pollution, and soil contamination, by conserving natural resources, minimizing energy consumption, and creating regional employment opportunities ${ }^{[4,5]}$. Recycled plastics are becoming good economical alternatives to virgin resin materials in manufacturing various plastic products. With improvement in recycling technology, most plastic manufacturers have begun using recycled resins as an alternative to virgin resin. Recycled plastics can be used in many applications: construction, automotive, packaging, agriculture, toy, composites, and so on.

The properties of recycled plastics are not as good as those of virgin plastics since the resins generally consist of various additives of different natural and synthetic compounds in order to improve manufacturability, stability, durability, and strength ${ }^{[2-6]}$. These additives are used as antioxidants, heat and light stabilizers, plasticizers, impact-resistance enhancers, pigments, colorants and dyestuffs, fire retardants, mold-release agents, foaming agents and filler materials. Other additives are used as antiblockers, anti-static agents, anti-foggers, biostabilizers, chemical blowing agents, lubricants, cross-linking agents, optical brighteners, metal deactivators, property modifiers, smoke and afterglow suppressants, and wetting agents ${ }^{[7]}$.

Polystyrene (PS) is one of the most common forms of plastics used in daily life. This lightweight material is produced in many commercial foam products, such as styrofoam, and utilized in disposable cutlery, toys, disposable drinking cups, egg cartons, packaging, CD and 
DVD cases, cassette tape housings, and more. PS is very versatile, but not biodegradable and not easy to recycle. Recycling of PS can be done by mechanical, chemical, and thermal processing techniques ${ }^{[2]}$. High-impact PS is an outstanding material for mechanical recycling since its properties are not generally affected during reprocessing ${ }^{[2]}$.

The objectives of this study were to encapsulate multiwall carbon nanotubes (MWCNTs) and NiZn ferrite $\left(\mathrm{Ni}_{0.6} \mathrm{Zn}_{0.4} \mathrm{Fe}_{2} \mathrm{O}_{4}\right)$ nanoparticles with recycled PS; produce nanocomposite fibers by means of electrospinning; and determine the thermal, electrical, magnetic, and surface properties of the electrospun nanocomposite fibers for various industrial applications. These applications may include air, water, and oil filtration; HF antennas; light weight, colorful, and invisible fabrics; thermal insulators; advanced composites; battery and supercapacitor separators; and interior noise reduction in aircraft, ships, trains, automobiles, manufacturing facilities, schools, hospitals, and other infrastructures.

MWCNTs and NiZn ferrite nanoparticles were added into the electrospun fibers in order to improve the mechanical, thermal, electrical, magnetic and other physical properties of the nanocomposite fibers. Carbon nanotubes (CNTs) are promising reinforcement materials for polymers and other materials because of their excellent mechanical $\left(\sigma_{\mathrm{UTS}}=150 \mathrm{GPa}\right)$, thermal $(K$ $\left.=1500-3000 \mathrm{~W} \mathrm{~m}^{-1} \mathrm{~K}^{-1}\right)$, and electrical $\left(\sigma=10^{4} \mathrm{~S} / \mathrm{cm}\right)$ properties $^{[7]}$. The traditional filler materials for increasing the physical properties of polymers include carbon fibers, metal or ceramic particles, graphene, clay, etc. Various types of reinforcement materials, such as CNTs, and other metals and ceramics are being widely used in polymer matrices to fabricate different composites with tunable physical properties ${ }^{[8]}$. NiZn ferrite nanoparticles are highly magnetic (26.8 emu/g) and stable nanomaterials, which can significantly improve the overall magnetic properties of the resultant nanoproducts using the recycled PS.

\subsection{Electrospinning}

Recently, much attention has been given to the electrospinning process for fabricating various fibers with diameters ranging from about $100 \mu \mathrm{m}$ down to $3 \mathrm{~nm}^{[9]}$. Compared to bulksize fibers, fibers produced by electrospinning have a very high surface area, porosity, flexibility, and aspect ratio, with superior mechanical, electrical, and thermal properties ${ }^{[10]}$. Electrospinning involves the application of a high electrostatic field over a conductive capillary attached to a reservoir of a polymeric solution and conductive collection screen ${ }^{[9-11]}$. Upon 
applying the electrostatic field and increasing its strength to a critical value, charge species that accumulate on the surface of a pendant drop destabilize the hemispherical shape into a conical shape (Taylor's cone) ${ }^{[9]}$. Beyond the critical value, a charged jet of the polymeric solution is ejected from the apex of the cone to the collection screen via electrostatic forces ${ }^{[9]}$. These repulsive forces are responsible for thinning of the charged jet during its flight from the cone apex to the collection screen where fibers grow from micron size to nanosize ${ }^{[9]}$.

\section{Experimental}

\subsection{Materials}

PS water cups were collected from a local restaurant and, after cleaning and rinsing, chopped into smaller pieces using a scissors. Dimethylformamide (DMF) and MWCNTs with a diameter of $140( \pm 30) \mathrm{nm}$ and a length of $7( \pm 2) \mu \mathrm{m}$ were purchased from Fisher Scientific. NiZn ferrite $\left(\mathrm{Ni}_{0.6} \mathrm{Zn}_{0.4} \mathrm{Fe}_{2} \mathrm{O}_{4}\right)$ nanoparticles were prepared in our laboratory facilities.

In the fabrication of $\mathrm{NiZn}$ ferrite nanoparticles, three different soluble sulfates $-\mathrm{NiSO}_{4}$, $\mathrm{ZnSO}_{4}$, and $\mathrm{Fe}_{2}\left(\mathrm{SO}_{4}\right)_{3}$-all purchased from Sigma-Aldrich, were dissolved in deionized (DI) water and the solutions were heated to $80{ }^{\circ} \mathrm{C}$ with constant stirring at $750 \mathrm{r} / \mathrm{min}$ for $2-3 \mathrm{~h}$. A concentrated $\mathrm{NaOH}$ solution (Fisher Scientific) was added drop-wise into the previous solution to initiate the internal chemical reaction at high $\mathrm{pH}$ values between 10 and 11 . While $\mathrm{NaOH}$ was being added drop-wise, the $\mathrm{pH}$ value of the solution was measured by a $\mathrm{pH}$ meter. After an additional 2-3 h of agitation by a magnetic stirrer, completely formed NiZn ferrite nanoparticles $(20-30 \mathrm{~nm})$ began precipitating ${ }^{[10,11]}$. Fig. 1 shows the transmission electron microscopy (TEM) image of NiZn ferrite nanoparticles.

\subsection{Methods}

2.2.1. Fabrication of nanocomposite fibers. Different weight percentages of MWCNTs and NiZn ferrite nanoparticles were separately dispersed in the DMF solvent using 30 min of sonication, and then the chopped PS pieces (Fig. 2(a)) were added to the dispersion prior to $12 \mathrm{~h}$ of high-speed agitation at $50{ }^{\circ} \mathrm{C}$ on a hotplate. The prepared solution was transferred to a plastic 
syringe $(10 \mathrm{ml})$ connected to a capillary tube having an inside diameter of $0.5 \mathrm{~mm}$. A platinum electrode with a diameter of $0.25 \mathrm{~mm}$ was attached to a high DC supply. The spinning voltage, pump speed, and capillary tube to collector screen distance were $25 \mathrm{kV}, 2 \mathrm{ml} / \mathrm{h}$, and $25 \mathrm{~cm}$, respectively. After $24 \mathrm{~h}$ of room temperature (RT) drying on the grounded screen collector, the electrospun fibers were collected and further dried in an oven at $60{ }^{\circ} \mathrm{C}$ for $8 \mathrm{~h}$ to remove all residual solvent and trapped moisture. Fig. 2 shows the scanning electron microscopy (SEM) (JEOL Model JSM-6460LV) images of the various selected PS electrospun fibers. For characterizations of the nanocomposite fibers, at least five measurements were conducted on each sample and the results were averaged to obtain each data point.

2.2.2. Thermal conductivity measurements. Thermal conductivities of the PS nanocomposite fibers with MWCNTs and NiZn ferrite were determined using the comparative method, whereby the thermal conductivity of a known sample (generally a pure copper rod) is compared with the thermal conductivity of an unknown sample (nanocomposite fiber film). The unknown sample was sandwiched between two known samples (copper rods with thermal conductivity of $401 \mathrm{~W}$ $\mathrm{m}^{-1} \mathrm{~K}^{-1}$ at RT). Fig. 3 shows the arrangement of the thermal conductivity measurements of the PS nanocomposite films.

The top portion of the copper rod was wrapped with a heating coil for the current and voltage supplies at $0.2 \mathrm{~A}$ and $20 \mathrm{DC} \mathrm{V}$, respectively. The coil was heated by a power source (Elenco Precision Quad Power Four Linear Regulated Supplies) at the top, and ice water was placed at the bottom (sink), for the maximum heat transfer through the axial direction. This current and voltage supply was adjusted in order to limit the temperature between 70 and $80{ }^{\circ} \mathrm{C}$. The purpose of limiting the temperature was to avoid/minimize the radiation/convection of heat loss. The whole assembly was first insulated with glass fiber, and then Teflon tape was placed on top. Four thermocouples (K-type) - two at the top of the sample (thermocouples 1 and 2) and two at the bottom of the sample (thermocouples 3 and 4) —were attached on the assembly (Fig. 3). A sensitive multimeter (Extech Industries Multiview 110) was used to measure the difference in millivolts. A compressive stress of around $1 \mathrm{kPa}$ was applied to the top of the assembly in order to minimize voids/wrinkles, and provide good contacts between the copper rods and fiber samples. A steady-state condition was usually achieved after a three-hour test duration, at which time measurements were accurately taken between points 1, 2 and 3, 4. The average temperature 
between points was compared with the temperature difference across the sample, and the thermal conductivity of the samples was determined as follows ${ }^{[8]}$ :

$$
\left.\begin{array}{l}
q_{12}=\frac{K_{\mathrm{cu}} A \Delta T_{12}}{\Delta x_{12}} \\
q_{34}=\frac{K_{\mathrm{cu}} A \Delta T_{34}}{\Delta x_{34}}
\end{array}\right]=q_{\mathrm{Avg}}=\frac{K_{\mathrm{S}} \Delta T_{23} A}{\Delta x_{23}}
$$

where $K_{\text {cu }}$ (copper) is the thermal conductivity of the references; $A$ is the area of the crosssection of the copper rod $\left(1.47 \times 10^{-4} \mathrm{~m}^{2}\right) ; K_{\mathrm{S}}$ is the thermal conductivity of the sample, $q_{\mathrm{Avg}}$ is the average heat flux between points 1,2 and 3, 4, $\Delta x_{12}, \Delta x_{34}$, and $\Delta x_{23}$ are the distances between upper and lower points and distance across the sample, respectively; and $\Delta T_{12}, \Delta T_{34}$, and $\Delta T_{23}$ are the temperature differences between those points, respectively.

2.2.3. Capacitance measurements. Dielectric constant values of the PS nanocomposite fibers incorporated with MWCNTs and NiZn ferrite nanoparticles were determined by using a capacitance bridge (TENMA72-370CRL). A parallel plate capacitor was employed to measure the capacitance values of the prepared samples. Fig. 4 shows the schematic representation of the capacitance measurement using ASTM D 150 test. The dielectric constant $\left(\varepsilon_{\mathrm{r}}\right)$ can be obtained from the measured capacitance $(C)$ with the help of electrodes of a known cross-section area $(A)$, layer thickness $(d)$, and vacuum dielectric constant $\left(\varepsilon_{0}, 8.85 \times 10^{-12} \mathrm{pF} / \mathrm{m}\right)$, using the following equation:

$$
\varepsilon_{\mathrm{r}}=\frac{C d}{A \varepsilon_{0}}
$$

2.2.4. Contact angle measurements. The water contact angle values of the PS nanofiber samples were determined using an optical contact angle goniometer purchased from KSV Instruments Ltd. (Model\#CAM 100). This goniometer is a compact, video-based instrument used to measure contact angles between $1^{\circ}$ and $180^{\circ}$ with an accuracy of $\pm 1^{\circ}$. Computer software provided by KSV Instruments Ltd. precisely measures the contact angles and also takes the pictures of the measured contact angle values. Samples were washed with DI water and dried in a vacuum overnight. Then they were placed on the goniometer stage, and a droplet of water was gently dropped on the sample by a syringe attached to the goniometer. 
2.2.5. VSM measurements. NiZn ferrite nanoparticles are one of the most versatile soft magnetic materials due to their high resistivity and permeability, low dielectric loss, and high

Curie temperature ${ }^{[8]}$. In the present study, the vibrating sample magnetometer (VSM) method was used to measure the magnetic properties of NiZn ferrite-based nanocomposite fiber samples at RT. A hysteresis loop of the sample was developed when the magnetic field was swept from 8,000 Gauss to $-8,000$ Gauss and back to 8,000 Gauss over a period of $30 \mathrm{~min}$. The magnetic moments of each magnetic sample were measured. The specific magnetic saturation values of the nanocomposite fibers were then calculated for each electrospun sample by dividing the saturation magnetization with its initial mass ${ }^{[12]}$.

\section{Results and Discussion}

\subsection{Thermal properties of fibers}

Fig. 5 shows the thermal conductivity values of the electrospun PS nanocomposite fibers in the presence and absence of MWCNTs and NiZn ferrite nanoparticles (20-30 nm). As can be seen, the thermal conductivities of 0, 2, 4, and $8 \mathrm{wt} \%$ of MWCNTs are 0.09, 0.15, 0.19, and 0.22 $\mathrm{W} \mathrm{m}{ }^{-1} \mathrm{~K}^{-1}$, while that of NiZn ferrite nanoparticles are 0.090, 0.092, 0.095, and $0.16 \mathrm{~W} \mathrm{~m}^{-1} \mathrm{~K}^{-1}$, respectively. These results indicated that $144 \%$ and $78 \%$ improvement in thermal conductivities could be achieved at higher concentrations of MWCNTs and NiZn ferrite nanoparticles, respectively. The higher thermal conductivity in MWCNT-based nanocomposite fibers is mainly because of the higher thermal conductivity of MWCNTs (1600 $\mathrm{W} \mathrm{m}^{-1} \mathrm{~K}^{-1}$ ) compared to NiZn ferrite nanoparticles $\left(6.3 \mathrm{~W} \mathrm{~m}^{-1} \mathrm{~K}^{-1}\right)$. NiZn ferrite is also a semi-conducting material having a spinel structure, which may affect the overall thermal properties ${ }^{[8]}$. The increase in thermal conductivity of MWCNT-based fibers is still considerably lower than what was initially expected, which may be because of the air pockets in the fiber film, interfacial resistance between different layers of MWCNTs, agglomerations, phonon scattering, and interfacial resistance between the polymer chains and MWCNT surfaces ${ }^{[11]}$.

PS is usually available in three forms: syndiatactic, atactic, and isotactic. Syndiatactic is crystalline, acatic is amorphous, and isotactic is semi-crystalline. Since the recycled PS pieces were extracted from drinking water bottles, the structure and crystallinity of this particular 
polymer could not be identified. The crystallinity of polymer affects physical, chemical, and physicochemical properties, so further studies will be conducted in future investigations to clarify this issue.

The thermal conductivity of a solid is mainly through the movement of phonons and heat conduction. Primary (ionic, covalent, and metallic) and secondary (van der Waals and hydrogen) bonds can also influence the thermal conductivity of materials ${ }^{[13,14]}$. The thermal conductivity of solid materials is generally affected by phonon scattering. Other factors influencing thermal conductivity include amorphous and crystalline regions of the polymer, chemical bridging, and entanglement of molecular chains ${ }^{[14]}$. In the fibrous form, thermal conductivity may also be dependent on crystallinity, chain orientation, length of molecular chains, amorphous and crystalline regions, and chemical bridge points ${ }^{[14]}$.

\subsection{Dielectric properties of fibers}

Fig. 6 shows the dielectric constant values of the nanocomposite fibers of MWCNTs and NiZn ferrite nanoparticles. The dielectric constant values of the fibers linearly increase with increasing addition of nanoscale inclusions in the PS fibers. For instance, the dielectric constant values of $8 \mathrm{wt} \%$ MWCNTs and $8 \mathrm{wt} \%$ NiZn ferrites in the PS fibers are 6.1 and 7.2, respectively. The dielectric properties of polymer are mainly associated with the structure (polar or non-polar), frequency, temperature, moisture, and internal/external defects ${ }^{[15]}$. MWCNTs are hydrophobic and conductive, while $\mathrm{Ni}_{0.6} \mathrm{Zn}_{0.4} \mathrm{Fe}_{2} \mathrm{O}_{4}$ nanoparticles are hydrophilic and semiconductive materials; however, PS is hydrophobic, non-polar, and non-conductor material. Both MWCNTs and ferrites contain more charge-carrying concentration capacities than the PS, and the incorporation of MWCNTs and ferrites in the PS matrix drastically increases the number of dipole moments in the matrix, thereby increasing the polarizability of the nanocomposite fibers $^{[19]}$. The major reasons for higher dielectric constant values of MWCNT-based fibers compared to ferrite-based fibers for the same weight percentage of filler materials may be because of the higher charge-storing capacity, polarizability, conductivity, crystallinity, and specific heat capacity of the inclusions.

Additionally, polymers with nanoscale additives provide resistance to environmental degradations and improvement in other physical, chemical, and physicochemical properties ${ }^{[11,12]}$. 
Nanoparticles have a larger surface area-to-volume ratio, and the surface area substantially increases as the size of nanoparticles decreases. High surface area means that there will be a higher interfacial area between the nanoparticles and the polymer matrix. This interfacial area, also known as the interaction area, significantly impacts the properties of the nanocomposites ${ }^{[16]}$. Some studies have emphasized that the interaction zone is a "quasi-conductive" region, which partially overlaps the nanocomposites. This region may allow charge dissipation, which in turn will improve the dielectric breakdown strength and voltage endurance properties ${ }^{[16-18]}$. Some authors have noted that when the size of the filler material approached the conformation length of the polymer, it acted cooperatively with the polymer structure by eliminating/suppressing the Maxwell-Wagner polarization ${ }^{[19]}$. Changes in morphology and surface characteristic can also influence these behaviors of nanocomposites ${ }^{[20]}$.

\subsection{Surface hydrophobic properties of fibers}

Table 1 provides the water contact angle values of the MWCNT- and NiZn ferrite-based nanocomposite fibers. Superhydrophobic surfaces (water contact angle $<150^{\circ}$ ) are governed by chemical composition and microstructure of the surface ${ }^{[21,22]}$. Thus, the hydrophobicity of surfaces can be improved by chemical modification and surface roughness. MWCNTs can increase both hydrophobicity and surface roughness, which may be why a small addition of MWCNTs in the PS nanocomposite fibers can show high contact angles compared to the ferritebased nanocomposites. As can be seen, the ferrite-based nanocomposite fibers became superhydrophobic when the weight percentage of the ferrites was increased considerably. The MWCNT-based nanocomposite fibers showed a superhydrophobic behavior at even $1 \mathrm{wt} \%$. The adhesion of a water droplet on the PS fiber surface may be similar to the adhesion mechanism of gecko's $^{[23]}$. If the number of nanotubes/nanofillers on the PS surface is higher, the Vander Waalsand hydrophobic forces can be higher too, resulting in a strong repulsion between the PS and water droplets, and subsequently higher water contact angle values.

A hydrophobic surface of the electrospun fibers has a static charge accumulation because of the electrostatic field applied during electrospinning, so the electrostatic charge may cause fire or an explosion in dry conditions. Therefore, fabrication of a superhydrophobic surface with high electrostatic conductivity can be an effective way of eliminating this danger by easily dissipating 
the static charge on fibers ${ }^{[21]}$. Overall, the produced superhydrophobic fibers can be used in many practical applications, such as self-cleaning, stain-resistant fabrics, antifouling surfaces, microelectromechanical systems, nanoelectromechanical systems, microfluidics, nanofluidics, and so on.

\subsection{Magnetic properties of fibers}

Fig. 7 shows the magnetization hysteresis loops of the NiZn ferrite nanoparticles in the recycled PS fibers. The relevant data of coercivity $\left(H_{\mathrm{c}}\right)$ and saturation magnetization $\left(M_{\mathrm{s}}\right)$, and the specific remnant magnetization $\left(M_{\mathrm{r}}\right)$ can be determined using these curves. The saturation magnetization values of the fibers increase as a function of the ferrite nanoparticles. For example, the saturation magnetization value of pure NiZn ferrite nanoparticles is $26.81 \mathrm{emu} / \mathrm{g}$, while those of 7.5, 15, and $30 \mathrm{wt} \%$ NiZn ferrite nanoparticles in the PS fibers are approximately 2,4 , and $8 \mathrm{emu} / \mathrm{g}$, respectively. In addition, the magnetization saturation occurred more quickly in the nanocomposite fibers with a lower weight percentage of the ferrite nanoparticles. For example, saturations values of $7.5 \mathrm{wt} \%$ and $30 \mathrm{wt} \%$ ferrite nanoparticles are 2,000 $\mathrm{G}$ and 3,000 $\mathrm{G}$, respectively. The saturation magnetization of pure ferrite nanoparticles is approximately $6,000 \mathrm{G}$.

The magnetic behavior of nanoparticles depends on particle size as well ${ }^{[24]}$. When the particle size approaches a certain size to form a wall of a magnetic domain, some properties, such as superparamagnetism, quantum tunneling of magnetization, and magnetocaloric effects can be observed in the magnetic nanocomposite fibers. However, the dispersion/agglomeration, oxidation, and shapes of nanoparticles in polymer matrix can significantly influence the magnetic properties of the nanocomposite fibers ${ }^{[24]}$. Recently, nanomaterials in fibrous form

have attracted much attention due to their large surface area, high aspect ratio, and anisotropy ${ }^{[8]}$. The NiZn ferrite with a spinel structure is a magnetic semiconductor with high electrical resistivity and high magnetic permeability, especially suitable for high-frequency device applications $^{[25]}$.

\section{Conclusion}


Recycled PS was converted into fibrous forms of nanostructured materials by using an electrospinning technique with the addition of nanofiller materials (e.g., MWCNTs and NiZn ferrite) in order to explore their possibilities for usage in many industrial applications. Various characterization techniques were used to determine some properties of these nanostructured materials. Test results showed the enhancement in the thermal conduction, dielectric constant, and superhydrophobic properties of recycled PS fibers. The ferrite-based electrospun PS fibers also showed a superparamagnetic behavior. Overall, this study may open up new possibilities to improve the properties of recycled plastics in different forms of nanomaterials for diverse industrial applications, such as filtration, transportation, construction, energy, defense, and so on.

\section{Acknowledgments}

The authors gratefully acknowledge the Department of Energy (DE-EE0004167) and the Wichita State University for financial and technical support to the present work.

\section{REFERENCES}

[1] N.M. Abdullah, I. Ahmad, Fiber. Polym. 14 (2013) 584-590.

[2] R.J. Reddy, W.S. Khan, In: Proceedings of the ASME International Mechanical Engineering Congress and Exposition, British Columbia, Canada, November 12-18, 2010.

[3] T. Maharana, Y.S. Negi, B. Mohanty, Polym.-Plast. Technol. Eng. 46 (2007) 729-736.

[4] H. Daewoo, S. Andrew, Langmuir 25 (2009) 9454-9462.

[5] S.R. Rao, Resource Recovery and Recycling from Metallurgical Wastes, Waste Management Series, Elsevier, 2006.

[6] W.S. Khan, R. Asmatulu, Y.H. Lin, Y. Chen, J. Ho, J. Nanotechnol. 2012 (2012), Article ID 138438, DOI: http://dx.doi.org/10.1155/2012/138438.

[7] S. Davluri, W.S. Khan, In: Proceeding to ASME International Mechanical Engineering Congress and Exposition, Orlando, Florida, U.S., November 13-19, 2009.

[8] W.S. Khan, R. Asmatulu, I. Ahmed, T.S. Ravigururajan, Int. J. Therm. Sci. 71 (2013) $74-$ 79.

[9] W. Patcharaporn, S. Pitt, S. Toemsak, K. Teerakiat, O. Tanakorn, J. Polym. Sci. Pt. BPolym. Phys. 43 (2005) 1881-1891.

[10] Q. Liang, X. Shen, F. Song, M. Liu, J. Mater. Sci. Technol. 27 (2013) 996-1000. 
[11] W.S. Khan, R. Asmatulu, Y.H. Lin, Y. Chen, J. Ho, J. Nanotechnol. 2012 (2012), Article ID 138438, DOI: http://dx.doi.org/10.1155/2012/138438.

[12] D.P. Yang, L.K. Lavoie, Y.D. Zhang, Z.T. Zhang, S.H. Ge, J. Appl. Phys. 93 (2003) 74927494.

[13] A.A. Bahgat, M.G. Moustafa, E.E. Shaisha, J. Mater. Sci. Technol. 29 (2013) 1166-1176.

[14] B.D. Mergenthaler, M. Pietralla, S. Roy, G.H .Killan, Macromolecules 25 (1992) 35003502 .

[15] F.M. Fréchette, M.L. Trudeau, D.H. Alamdari, S. Boily, IEEE Trans. Dielect. Elect. Insul. 11 (2004) 808-818.

[16] Y. Atsuhiko, T. Tomoaki, ISRN Mater. Sci. 2011 (2011) Article ID 718761, 10 pages.

[17] M. Roy, K.J. Nelson, K.R. Maccrone, S.L. Schadler, W.C. Reed, R. Keefe, W. Zenger, Dielect. Elect. Insul. 12 (2005) 629-643.

[18] W. Peukert, C.H. Schwarzer, M. Götzinger, L. Günther, F. Stenger, Adv. Powder Technol. 14 (2003) 411-426.

[19] J.T. Lewis, IEEE Trans. Dielect. Elect. Insul. 1 (1994) 812-825.

[20] K.J. Nelson, C.J. Fothergill, Nanotechnology 15 (2004) 586-595.

[21] X.L. Chen, S.Y. Wei, C. Gunesoglu, J.H. Zhu, C.S. Southworth, L.Y. Sun, A.B. Karki, D.P. Young, Z.H. Guo, Macromol. Chem. Phys. 211 (2010) 1775-1783. ,

[22] X.B. Lu, J.H. Zhou, Y.H. Zhao, Y. Qiu, J.H. Li, Chem. Mater. 20 (2008) 3420-3424.

[23] A. Kellar, P.M. Anne, Biolog. Sci. 42 (2002) 1081-1090.

[24] W.S. Khan, R. Asmatulu, R.M.M. Eltabey, J. Nanotechnol. Eng. Med. 1 (2010) 1-6.

[25] M.H. Jin, X.J. Feng, L. Feng, T.L. Sun, J. Zhai, T.J. Li, L. Jiang, Adv. Mater. 17 ( 2005) $1977-1981$. 


\section{Table and Figure Captions}

Table 1 Water contact angle values of PS nanocomposite fibers

Fig. 1 TEM image of NiZn ferrite nanoparticles used in the present study.

Fig. 2 Photographs showing the recycled and chopped PS (a), SEM images of electrospun PS fibers (b), PS fibers with 4 wt\% MWCNTs (c), and PS fibers with 30 wt $\%$ NiZn ferrite nanoparticles (d).

(b) electrospun PS fibers, (c) PS fibers with 4wt\% MWCNTs, and (d) PS fibers with 30wt\% NiZn ferrite nanoparticles.

Fig. 3 Experimental arrangement of thermal conductivity measurements.

Fig. 4 Schematic representation of dielectric constant measurement by using an ASTM D 150 test.

Fig. 5 Thermal conductivity values of PS nanocomposite fibers as function of MWCNTs (a) and NiZn ferrite concentrations (b).

Fig. 6 Dielectric constant values of PS nanocomposite fibers as function of MWCNTs (a) and NiZn ferrite concentrations (b).

Fig. 7 Magnetization hysteresis loops of NiZn ferrite-based PS nanocomposite fibers.

Table 1

\begin{tabular}{cccc}
\hline MWCNTs (wt\%) & $\begin{array}{c}\text { Water contact angle } \\
(\mathrm{deg} .)\end{array}$ & Ferrites (wt\%) & $\begin{array}{c}\text { Water contact angle } \\
(\mathrm{deg} .)\end{array}$ \\
\hline 0 & 135.0 & 0 & 135.0 \\
1 & 152.9 & 7.5 & 142.2 \\
2 & 154.3 & 15 & 146.7 \\
4 & 156.9 & 30 & 150.7 \\
\hline
\end{tabular}




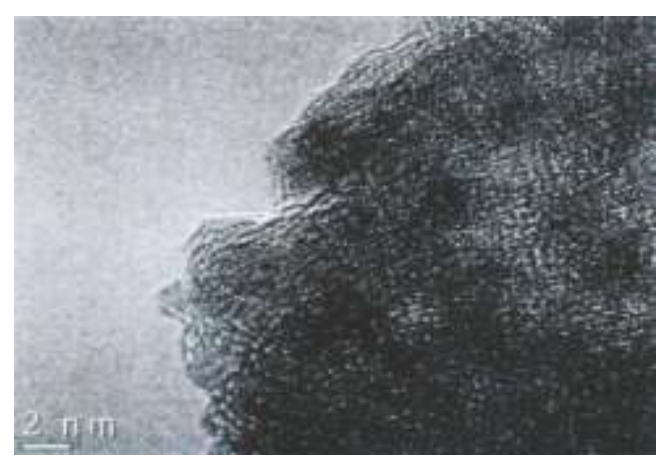

Fig. 1
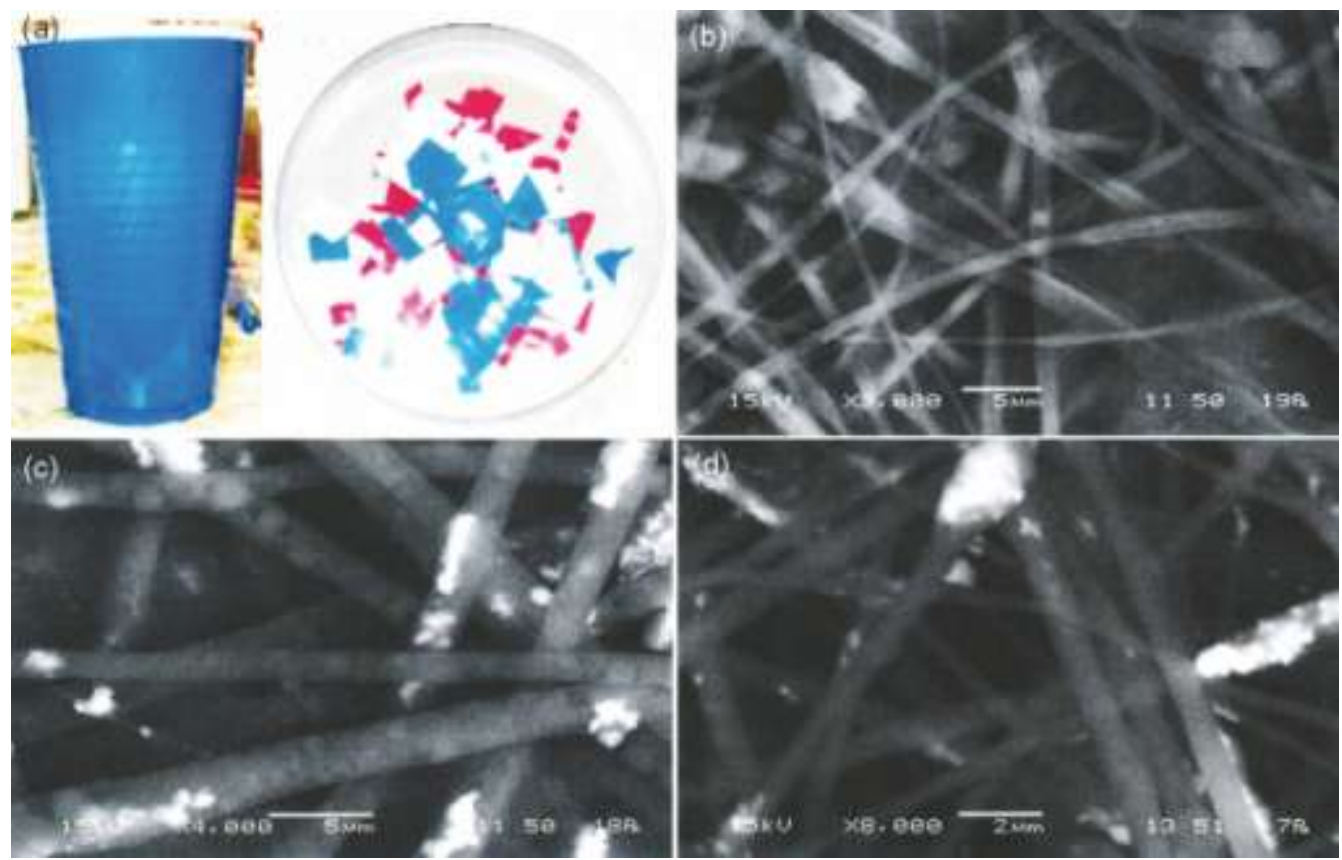

Fig. 2

Compressive Stress

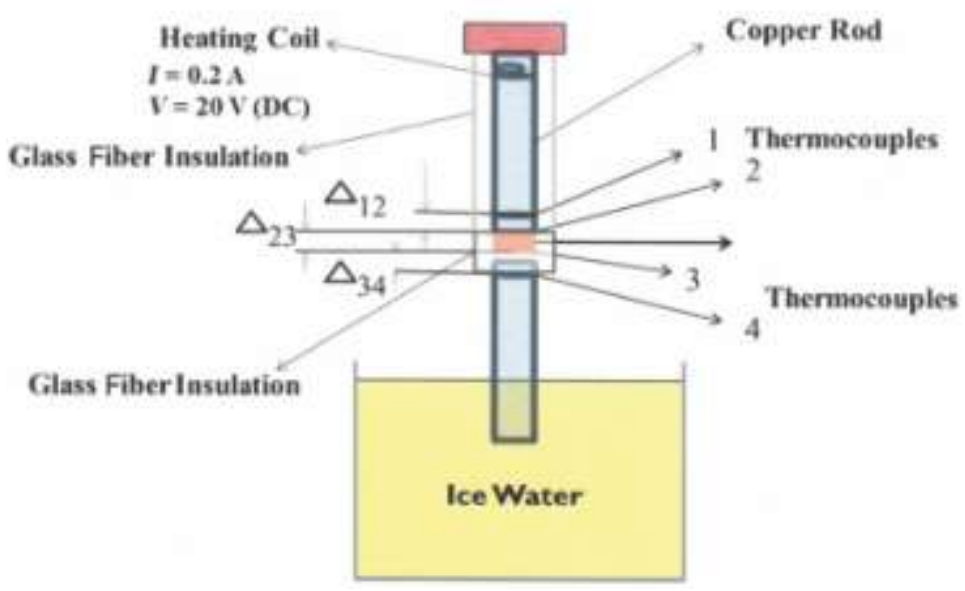

Fig. 3 


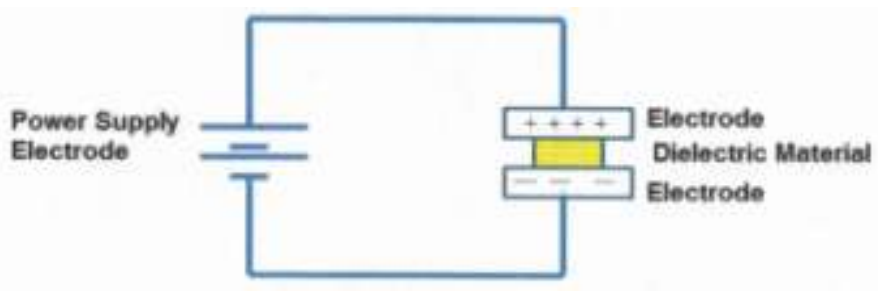

Fig. 4

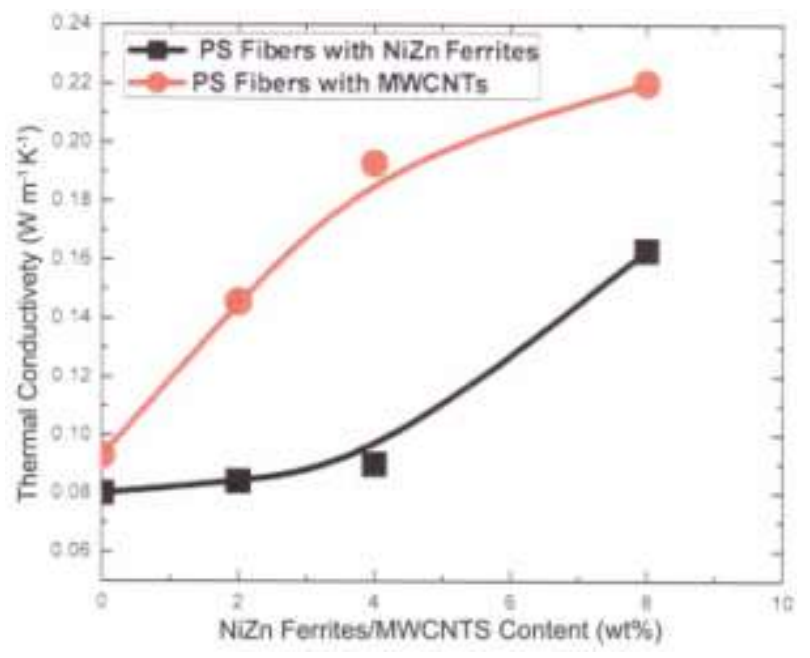

Fig. 5

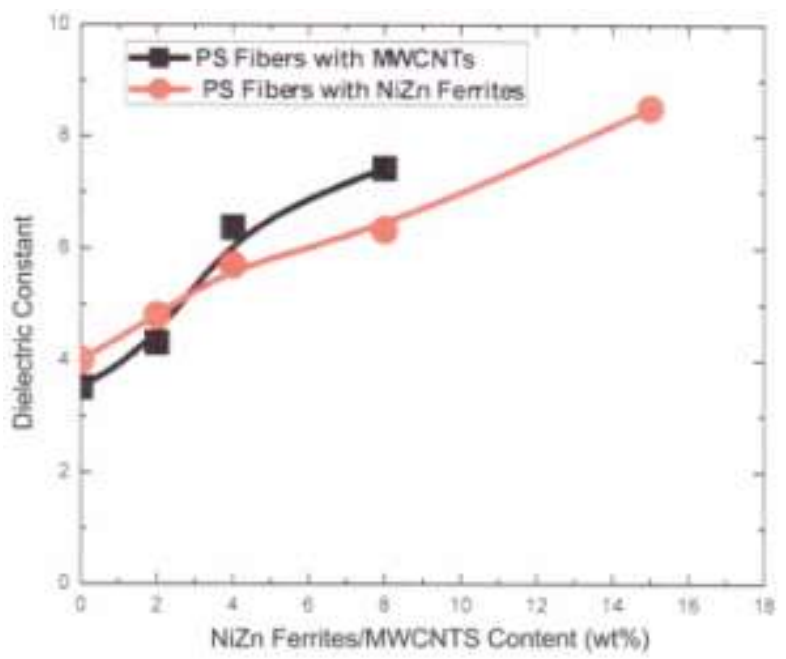

Fig 6 


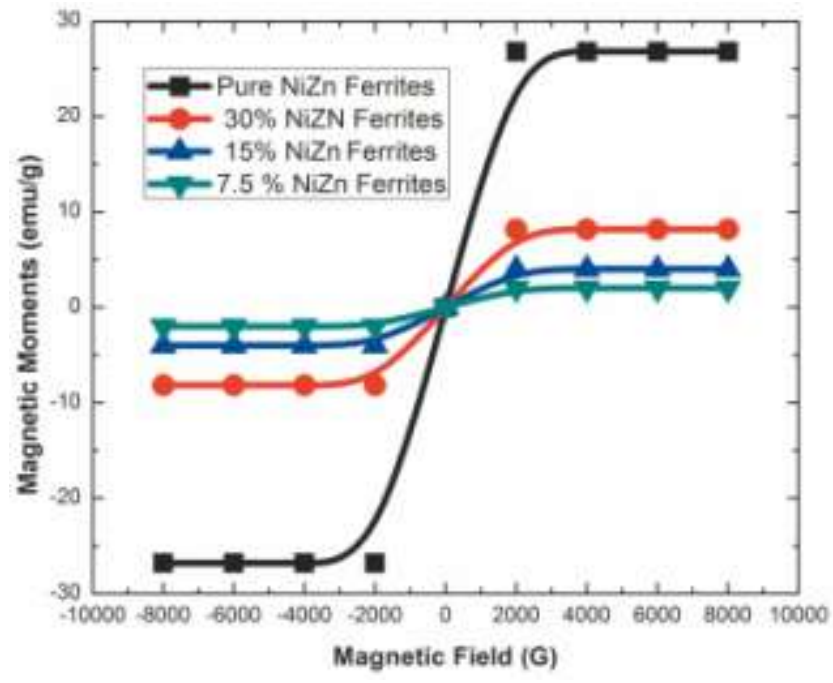

Fig 7 